\title{
'She had a Smile on her Face as Wide as the Great Australian Bite': A \\ Qualitative Examination of Family Perceptions of a Therapeutic Robot and \\ a Plush Toy
}

Running title: FAMILY PERCEPTIONS OF PARO AND PLUSH TOY

Professor Wendy Moyle PhD ${ }^{a, b^{*}}$ w.moyle@griffith.edu.au

Dr Marguerite Bramble $\mathbf{P h D}^{\mathbf{c}} \underline{\text { mbramble@ csu.edu.au }}$

Dr Cindy J Jones PhD ${ }^{\text {a,b }}$ c.jones@ griffith.edu.au

Ms Jenny E Murfield BSc(Hons) ${ }^{\mathbf{a}}$ j.murfield@ griffith.edu.au

${ }^{a}$ Menzies Health Institute Queensland, Griffith University, Nathan, Brisbane, Queensland, Australia

${ }^{\mathrm{b}}$ School of Nursing and Midwifery, Nathan Campus, Griffith University, Nathan, Brisbane, Queensland, Australia

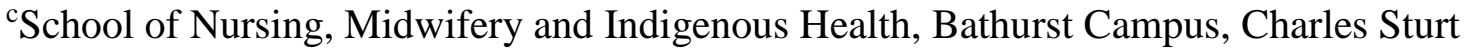
University, Bathurst, New South Wales, Australia

Address correspondence to Professor Wendy Moyle, Menzies Health Institute QLD, Griffith University, 2.10 Health Sciences (N48), 170 Kessels Road, Nathan, Brisbane, Queensland, 4111, Australia. Tel: +61 73735 5526; Fax: +61 73735 5431; Email:

w.moyle@griffith.edu.au

\section{Funding}

This work was supported by a grant from the Australian National Health and Medical Research Council (1065320). 


\section{Acknowledgements}

Thanks are expressed to all aged care organisations, facilities, care staff, residents, and families who so generously took part in the research. Specific thanks are also extended to Dr. Jasmin Grayson-Collins for project management, cluster leadership, and help with conducting some of the interviews, and to Amanda McNiven for cluster leadership. The following members of the larger Paro study, who were not involved in the qualitative interviews and analysis, are also acknowledged for their contribution to the Paro protocol: Professors Elizabeth Beattie, Brian Draper, David Shum, and Lukman Thalib; and Drs Siobhan O’Dwyer and Cindy Mervin.

\section{Conflicts of Interest}

Wendy Moyle was personally loaned equipment (five of the Paro) for the duration of the cluster-RCT by the developer, Dr. Takanori Shibata. Dr. Shibata provided no monetary support for the study, and had no role in any aspect of the study design, undertaking data analysis and results interpretation, and in the reporting of the findings and preparation of the manuscript. All other authors declare no financial, personal, or potential conflicts of interest.

\section{Description of Authors' Role}

Wendy Moyle conceived and designed the larger study, in consultation and review with Cindy Jones. Wendy Moyle and Marguerite Bramble oversaw the qualitative data collection, and Marguerite Bramble conducted the interviews. Wendy Moyle and Marguerite Bramble analysed the data and prepared a first manuscript draft. All authors provided conceptual comment and revision, and approved the final version on the manuscript. 


\title{
'She had a Smile on her Face as Wide as the Great Australian Bite': A Qualitative Examination of Family Perceptions of a Therapeutic Robot and \\ a Plush Toy
}

\begin{abstract}
Background and Objectives: Recent years have seen social robotic pets introduced as a means of treating behavioural and psychological symptoms of dementia, and many show promising potential. In this study, we sought to explore family members' perceptions of the Japanese-developed baby harp seal, Paro (version 9), and a look-alike, non-robotic Plush
\end{abstract} Toy, when used by their relative with dementia for 15-minutes, three afternoons per week for 10 weeks.

Research Design and Method: The study employed a descriptive qualitative approach, which was nested within a larger cluster-randomised controlled trial. A convenience sample of 20 family members ( $n=10$ each from the Paro and Plush Toy conditions) with relatives in nine long-term care facilities in Queensland, Australia, completed individual semi-structured interviews (telephone or face-to-face). Inductive, data-driven thematic analysis of the data was undertaken with the assistance of the qualitative management software, ATLAS.ti ${ }^{\circledR}$.

Results: Family members of long-term care residents with dementia expressed positive perceptions of the Paro, perceiving that it improved mood, reduced agitation, and provided opportunity for communication for their relative. Negative perceptions of the Plush Toy were given by family members, primarily because of its lack of movement and engagement.

Conclusion: Family members were keen for their older relative with dementia to use a social robot that moved and engaged with them, and Plush Toys that were static and unresponsive were perceived as being unimportant in improving quality of life. However, the current cost of Paro was identified by family members as a major limitation to use.

Keywords: Social Robot, Long-Term Care, Dementia. 


\section{'She had a Smile on her Face as Wide as the Great Australian Bite': A Qualitative Examination of Family Perceptions of a Therapeutic Robot and a Plush Toy}

\section{Introduction}

The number of people with dementia is on the rise alongside an ageing population. The majority of people with dementia end their life in long-term care (LTC) facilities, with the proportion of people with dementia in these facilities ranging from over 50\% in Australia (Australian Institute of Health and Welfare, 2012) to over $80 \%$ in the UK (Prince et al., 2014). Further, of these, approximately one in five residents experience symptoms of dementia-related agitation (Morley, 2011). Presenting as verbal aggression, destructive and resistive behaviour, pacing, and repetitive questioning and motor behaviour, symptoms of agitation occur most commonly in people with mid-stage dementia and, for many, can be a result of unmet needs. These adverse behaviours can challenge the caregiving process, and this can result in stress and job dissatisfaction in staff members (Zimmerman et al., 2005), and can lead to diminished quality of life and functionality (Klapwijk, Caljouw, Pieper, van der Steen, \& Achterberg, 2016), as well as feelings of loneliness and social isolation (Moyle et al., 2011), for the person with dementia.

Behavioural and psychological symptoms of dementia (BPSD) such as agitation are treatable and, by doing so, offers the best chance to alleviate suffering, reduce family burden, and lower societal costs in people with dementia (Cummings et al., 2015). Historically, psychotropic medication has been the first-line of treatment for alleviating BPSD. However, in light of limited efficacy and potential harmful side-effects of pharmacological approaches (Moyle et al., 2017), psychosocial approaches are now advocated as the primary treatment for symptomatic benefit of BPSD (Banerjee, 2009). 
Residents in LTC facilities often spend the majority of their time alone and with limited stimulation of the senses, empty conversation, or engagement in meaningful activities (Moyle et al., 2011). This lack of stimulation can be particularly detrimental to people with dementia, as it can adversely affect their mood, increase their level of agitation, and result in a high use of pharmaceutical intervention (Moyle et al., 2016b). To address this, social robots have recently been used as a treatment for BPSD, engaging humans in life-like social behaviour and interacting with people by encouraging engagement, embodiment, and interaction in an activity similar to pet therapy (Mordoch, Ossterreicher, Guse, Roger, \& Thompson, 2013). As technological advances take place, and robots become more costeffective, it is likely that we will see an increase in the use of social robots in future aged and dementia care. To date, a range of social robots have been developed for use within this population and, of these, the most commonly studied pet-type robot is Paro (Figure 1), a robotic harp seal developed in Japan by Dr. Takanori Shibata (National Institute of Advanced Industrial Science and Technology, Japan). Approximately the size of a newborn baby, Paro behaves like a pet by encouraging interaction and engagement through 12 sensors in its synthetic coat and whiskers. By stroking Paro, the robot responds by turning to the person, mimicking the sound of a seal, and moving its tail and paws. Through this engagement, Paro delivers companionship and affection to the individual. The robot was designed as a harp seal due to its unfamiliarity, thereby reducing negative associations users may have with more common household animals, such as dogs or cats.

Paro's potential for use with people with dementia has been shown in a handful of small-scale trials on outcomes including quality of life, engagement, agitation, and apathy (Joranson, Pedersen, Rokstad, \& Ihlebaek, 2015; Moyle et al., 2013; Petersen, Houston, Qin, Tague, \& Studley, 2017; Takayanagi, Kirita, \& Shibata, 2014; Thodberg et al., 2016). Building on this initial work, and addressing some of the shortcomings of the research 
conducted to date (Bemelmans, Gelderblom, Jonker, \& de Witte, 2012), we sought to establish Paro's efficacy to improve BPSD in a robust and rigorous cluster-randomised controlled trial (RCT) (Moyle et al., 2015). Involving 415 older people with dementia from 28 LTC facilities, we compared Paro (version 9) with a look-alike Plush Toy (Paro with the artificial intelligence turned off so that it did not move or respond), and Usual Care. Facilities were randomised to one condition only, and participating residents received individual, nonfacilitated, 15-minute sessions three afternoons per week (Monday, Wednesday, and Friday between 13:00 and 17:00) for 10-weeks, with either the Paro or a Plush Toy. Facilities in the Usual Care group continued care as standard. As we describe in detail elsewhere (Moyle et al., accepted for publication), we found that Paro had a modest but significant effect on BPSD, encouraging residents' verbal and visual engagement with the object, improving their expressions of pleasure and reducing their neutral affect, and having some effect in reducing agitation. In further qualitative work conducted after the completion of the RCT (Moyle, Bramble, Jones, \& Murfield, 2016a), we also found that care staff from participating facilities preferred the Paro to the Plush Toy, and perceived it as having particular potential to improve quality of life. However, staff were concerned that the current high cost of Paro $(\sim 8,500$ AUD) may prohibit use within LTC facilities.

Within this paper, we present our work exploring the perceptions of family members about the use of Paro and Plush Toy with their older relative with dementia in LTC. These findings complement the qualitative work undertaken exploring staff perceptions, and provide important insights into how families may specifically influence the use of Paro in the LTC setting.

[Insert Figure 1 about here] 


\section{Methods}

\section{Design}

This qualitative study was nested within a larger cluster-RCT that compared the effect of Paro with a look-alike Plush Toy (a Paro with all robotic features disabled), and Usual Care in reducing agitation, and improving mood states and engagement (Moyle et al., 2015; Moyle et al., accepted for publication). We chose a qualitative design to explore the individual family member's perception of the Paro robotic seal compared to the Plush Toy, and his/her experience in relation to BPSD. Family members did not facilitate their relatives' use of the Paro and Plush Toy during the trial - all sessions were un-facilitated - but they had opportunities to observe their relative during these sessions.

\section{Sampling Strategy}

Maximum variation sampling was used to identify a range of facilities (nine out of 19), from which family members involved in the larger cluster-RCT could be approached for interview. A convenience sample of twenty family members from the PARO $(n=10)$ and Plush Toy $(n$ $=10$ ) study conditions (facilities) was set a priori to achieve sufficient variation in the sample. This sample size was based on our previous work undertaken with care staff (Moyle et al., 2016a), which showed a total of 20 participants was sufficient to generate data-driven themes. However, if we felt data saturation was not achieved with this sample size we were prepared to extend the sample size. Fourteen family members or friends with relatives in the Paro condition were identified by facility managers as being interested in attending an interview, and the first ten with availability were interviewed. The same process was followed for the Plush Toy condition, with 12 family members identified by facility managers, and the first ten with availability interviewed. 


\section{Ethical Approval}

Ethical approval was obtained from Griffith University Human Research Ethics Committee (NRS/03/14/HREC), as well as respective care organisations, as required. Written informed consent was obtained from all participating family members at the time of interview. The study is registered with the Australian New Zealand Clinical Trials Registry (ACTRN12614000508673).

\section{Data Collection}

Two members of the research team conducted semi-structured interviews with family members of people with dementia who participated in the larger study two weeks following its completion. Interviews were conducted using a schedule focused on seven areas of questioning (Table 1), but permitted further probing in relation to responses, as necessary. All interviews were conducted either by telephone or face-to-face at the facility, and ranged in length from 30 to 45 minutes. Interviews were recorded using a digital audio recorder and then transcribed verbatim by an independent transcription service.

[Insert Table 1 about here]

\section{Data Analysis}

The qualitative management software, ATLAS.ti ${ }^{\circledR}$ (Scientific Software Development GmbH, Berlin), was used to support the researchers to inductively code and categorise the interview transcripts to produce data-driven codes. The codes were labels applied to words or phrases within the transcripts. Two members of the research team undertook the analysis separately, writing memos that were stand-alone or linked to quotations, or codes. The researchers then came together for a collective discussion and to share their results and to discuss in order to reach a consensus for each code. Codes were grouped into themes using an inductive 
thematic analysis (a bottom-up approach) to converge and compare themes across family member quotations (Braun \& Clarke, 2006). Themes were grouped according to family member's perceptions of the Paro or Plush Toy, and linked to the larger-RCT's primary outcomes of interest - agitation, mood states, and engagement (Table 2). Representative quotations are used to support the analysis, and family identification codes are outlined in Table 3.

[Insert Tables $2 \& 3$ about here]

\section{Findings}

Four daughters, three sons, and a wife, husband, and friend from the Paro condition were individually interviewed. In the Plush Toy condition, seven daughters, one son, and two wives agreed to be interviewed (Table 4).

[Insert Table 4 about here]

\section{Theme 1: Initial Perceptions of the Paro and Plush Toy as Stimulation, Comfort, and Companionship}

Family members' initial perceptions of the Paro were focused on their relatives' love of animals and their perception that their wellbeing would improve, "Because they love animals" [FD4]. Although there was a general perception that live animals would be better than animated ones, families consented for their family members to be involved in the study, as they hoped the animal robot would calm their relative. One daughter stated, “Anything's worth a try to make her a little more contented" [FD8]. A wife, who wished that the Paro would help settle her husband's agitation, also expressed this sentiment, "He was constantly how can I say it? Constantly on the go, like couldn't settle" [FW18]. As animal lovers and pet owners, family members understood how important pets had been in their relatives' lives and 
hoped Paro would provide meaningful activity ("My perception was that she would probably respond quite well to it because, as I say, she lived and breathed the dog when she had it" [FS12]). One family member thought the Paro would provide other therapeutic benefits, such as improved cognitive ability, and complement other therapies, such as reminiscence ("I thought it would be a sensory stimulation and actively involve the residents with the stimulation and help improve their cognitive ability as well by stimulating that too with memories and reminiscing, that type of thing" [FS13]).

Family members from the Plush Toy sites also talked as if the Plush Toy was another animal residents would enjoy ("There seemed to be a smile on the face of the residents when an animal came in. So, I would think that most would have a very positive response" [FS15]). One daughter from a Plush Toy site talked about the pleasure the seal might bring to her father ("I actually saw an article on the TV about it and I thought oh, that's interesting. What I saw was the pleasure on people's faces... then I was asked, would you like dad to be involved? I said, well I'd love it because dad was such an animal lover, he responds well to animals" [FD11]).

For all family members, their initial perceptions of the Paro and Plush Toy were of, "Something tactile, something that was moving, something that was stimulating" [FD9]. They hoped that this 'live animal' robot would provide stimulation, comfort and companionship, thus reducing anxiety and improving wellbeing for the resident.

\section{Theme 2: Changing Perceptions: Movement and Engagement vs. Non-Movement}

When family members witnessed their relative with dementia interact with the Paro, they were impressed with how the animal robot could provide a sense of responsibility and a connection to a familiar pet, such as a dog. Positive comments included, "She seemed very content just sitting there, patting the seal and looking at it" [FD3]; and "She really enjoyed 
having it there ... she was looking forward to it every day. She felt responsible for looking after it. She thought it was someone's dog" [FD4]. The importance of the animal robot in improving residents' wellbeing came through in the interviews. One daughter talked about the psychological triggers and emotional needs of her mother, whom she thought, "Needs that connection with an animal and actually think it's alive ... it does help psychologically" [FD6]. Another daughter talked simply about Paro providing stimulation and relieving boredom as, "She's always been bored in there [nursing home] .... So, she liked interacting with it because it gave her something to do" [FD7]. A third daughter talked in glowing terms about the improvement Paro had made in her mother's mood saying, "Mum just loved it. She talked to it. She had a smile on her face as wide as the Great Australian Bite. It definitely did make a difference to her mood" [FD8].

In comparison, family members' discussion about their changing perceptions of the Plush Toy was focused on disappointment and, specifically, the lack of movement and ability of the Plush Toy to interact with residents. Family members had assumed their relative was in the Paro group and were disappointed when they viewed the Plush Toy ("Well, it didn't move, it didn't make a noise" [FD1]). Families also perceived that their relative was not interested in the Plush Toy because of its lack of presence and therapeutic ability. One wife who visited her husband described her experience of the Plush Toy with her husband ("He didn't seem to be that interested" [FW16]). Another daughter commented that, "It was not like moving or anything, it was just .... I think he would be better with something that actually moves" [FD11].

\section{Theme 3: Paro's Ability to Reduce Behavioural and Psychological Symptoms of}

\section{Dementia}


When family members discussed the benefits of Paro they talked about its ability to reduce the behavioural and psychological triggers of dementia by providing stimulation and reducing agitation. They described the subsequent improvement in interpersonal relationships and social interaction as having 'something to love'. On further reflection, family members made positive comments about the effect of the Paro on residents' mood, such as, "Everybody I saw with it, it certainly seemed to lighten their mood" [FH19]; and "It's close companionship ... the fact that it reacts to the voice, can move when you pat it" [FD5]. One family member felt that, "It probably makes them think a little differently because there's another element in their life. It helped her get through the afternoons" [FD4].

Family members were particularly interested in the benefits of Paro that they associated with emotional and social engagement, and a reduction in loneliness and reminiscence ("Maybe just the interacting with the soft fur of the seal makes them remember perhaps when they were younger, or something like that ... there were some mornings when she seemed quite with it, and less agitated" [FD8]).

Some family members touched on the fact that it did not seem to matter whether it was a seal or a dog, as long as the resident perceived it to be real ("So I think for her it's a companion, somebody to talk to, she's not lonely, nowhere near as agitated because she's got nothing to do. She's got the dog to talk to - well the seal to talk to [laughs]" [FD7]).

In comparison, family members at the Plush Toy sites did not feel it had many, if any, benefits ("Not really, not when it's not working. It may be different if it did move or it did make a noise or whatever but, to me, no ... That was why I agreed to it, to the survey, because I anticipated that it would be like a little talking dog or something that he may have, perhaps, taken notice of. I was disappointed... - he wouldn't have known anyway. When I use a robotic seal, you imagine it moves or it makes noises. You don't imagine it just to be a fluffy toy" [FW16]). 
While the Plush Toy family members dwelled on the unresponsiveness of the Plush Toy, they also spoke of the benefits of giving a 'live animal' robot to their family member. For example, one son stated, "The normal human empathetic feelings that you might have when you're with your dog that you love, that sort of thing. It's still giving that tactile contact with some interaction of a live animal, without the problems of a live animal. .... the needs are still there. They still feel lonely. They still feel distressed. All of those human needs that are still there" [FS14].

\section{Theme 4: Limitations of the Paro and Plush Toy}

Although families were generally impressed with the Paro, the major limitation identified was the cost, with one family participant saying, "The experience is good, but I still think it's highly overpriced" [FD8]. Another commented, "If she had to pay $\$ 7,000$ or $\$ 400$ a month, yeah, it would limit it. I mean we've ended up with a (toy) dog for $\$ 50$ [purchased independently by the family after the trial] that seems to do the same thing" [FD7].

Another limitation centred on family participants concern about how their relative with dementia might respond to Paro. Concerns were mainly centred on the use of an intervention that may be seen by residents as being toy-like. For example, a participant commented that, "It's not real, and you could see that sometimes in some of the people. They may think that you're treating them like kids" [FD8]. Similarly, at the Plush Toy site, family members felt that residents with dementia could perceive it was, "Fake, and maybe that wouldn't work so well” [FD9]. In addition, family members at the Plush Toy site were concerned about the seal being an unfamiliar animal and, therefore, being seen as a 'fake animal' ("I have reservations about her really connecting there. Maybe a small puppy or something [would be better]" [FS15]). Other limitations about Plush Toy were that, "To me it 
was just a white furry thing that he didn't take much notice of" [FW16], and "Simply that it was inanimate. That it wasn't in any way going to respond to her" [FD10].

\section{Theme 5. Opportunities for Family Involvement}

All family members expressed interest in, and commitment to, being personally involved with the Paro as 'pet therapy', either as a group activity or alone with their relative in their room. As family members visited regularly, they knew the time of day most suited to their relative for therapeutic engagement with Paro. All family members, once again, focused their involvement on meaningful activities and mutual experiences to alleviate psychological triggers, to help keep their relative calm, provide stimulation, and something to love. As one family member suggested, "It'd be like taking one of our pets in" [FD7]. It is worth noting that all family members (except for one friend) had an extra layer of responsibility for their relative's well-being in their role as Power of Attorney. This may, arguably, add another dimension to their sense of commitment and should be borne in mind.

When discussing ways to be involved, daughters, in particular, revealed long-term intimate knowledge and tacit understanding of the impact of dementia on their parent. This tacit knowledge was reflected in one family member's comments about BPSD, such as agitation and visual agnosia ("If I have my dog or there is the seal, she concentrates on that rather than repetition .... It certainly makes the visit easier ..." [FD4]). She also talked about the "terrible tantrums" her mother has had "for years", and how the Paro would be a “distraction to settle her down and make her calm' [FD4]. Other daughters talked about how Paro would, "break the boredom of the day" [FD5] and, "... his animated talk. But they took that on for real. So, he was actually conversing with them (Paro) I guess" [FD8].

Spouses also wanted to be involved in utilising Paro to help fulfil individual needs of their partner. For example, one husband explained, "Rosemary loves to walk. So, if she was 
walking around the lake and she had Roy (Paro) sitting on her walker, I have no doubt she'd have a smile on her face the whole time" [FH19]. One wife suggested the Paro could help with her conversations and involvement, such as, "Well I would sit and talk to him about it or - if he was awake of course. I would sit and talk to him" [FW17].

\section{Theme 6: Robot Better than Live Animal}

Family members from both the Paro and Plush Toy sites thought that live animals were great for pet therapy but that a robotic animal would be better because, "You don't have to feed it, you don't have to clean up, it never gets sick" [FD4]. However, one participant stated, "I'd rather bring the dog. The only reason I don't bring him more frequently is, usually, I have washing (clean laundry to bring in) and the dog does jump. I've got to be very careful that I carry him in case he jumped on another resident" [FW16]. They also commented that the seal, "Doesn't get upset and kick and buck and scratch and carry on" [FH19]. One family member concluded, "I think the best way to go with this is things like the seal (Paro). I really do" [FW18]. This was summarised well by another family member ("Pet therapy and music therapy - I think are incredibly important, because they have that real interaction with a stimulating external environment [BUT] there's also the chance that someone could get bitten" [FD9]).

One family participant talked about the importance of Paro in communicating with the resident stating, "So with the noise that he makes and he talks. She (person with dementia) said he (Paro) answers me, he talks to me. When I ask him a question he talks to me. That type of thing, so as long as it was some sort of a reaction like that, yeah, I think they'd be quite happy to be a part of it" [FH19]. 
Although the Paro was designed as an unfamiliar animal, concerns about this were also raised. One family member commented that, "A more recognisable animal might be better. I mean mum would have recognised a dog toy" [FD1].

\section{Discussion}

In this qualitative investigation, we found that family members of LTC residents with dementia had a positive view of Paro. Families were keen for their relative to use a social robot that moved and engaged with them, perceiving that it improved mood, reduced agitation, and provided comfort and opportunity for communication for their relative. These findings are consistent with the only other known study that explored family members' views, where families saw Paro as a means of engagement for their relative with dementia, as well as offering interest, amusement, and also reassurance (Robinson, MacDonald, Kerse, \& Broadbent, 2013).

Regarding the use of a Plush Toy as a psychosocial intervention to ameliorate BPSD, family members held negative perceptions and deemed it unimportant in improving quality of life due to lack of movement and unresponsiveness. These negative sentiments are consistent with the views of facility staff members from the larger-RCT, where it was also expressed that Plush Toys were unbeneficial to the person with dementia due to their lack of movement (Moyle et al., 2016a). In addition, the views of families also lend support to our main analyses of the primary outcomes from the RCT, where we found that Paro was significantly more effective than the Plush Toy in encouraging verbal and visual engagement (Moyle et al., accepted for publication). This suggests that the robotic features of Paro may be central in encouraging resident engagement and interaction compared to a non-robotic Plush Toy equivalent. 
In terms of Paro's limitations, family members identified the current cost of Paro as its major limitation to use in LTC. Similar concerns were also expressed by facility care staff (Moyle et al., 2016a), suggesting that, despite recognising Paro's benefit for residents with dementia, the current cost of Paro may preclude uptake by those individuals caring for the person with dementia. An economic evaluation of Paro's cost-effectiveness is currently being undertaken as part of the larger RCT, and will provide much-needed information to inform budgetary decisions about purchasing Paro.

Another key finding emerging from this qualitative exploration was that families were eager for their older relative with dementia to be involved in the larger robotic RCT, as they perceived that the robot might help comfort their family member and may reduce their agitation and distress. Although families were informed in written information materials that their family member would be randomised to one of three conditions - Paro, Plush Toy, or Usual Care - they expressed their disappointment when the facility their family member resided in was allocated to receive the Plush Toy. These findings highlight the challenge of recruiting participants to RCTs, and to conditions that family perceive as not being important, but that are needed to allow rigorous treatment comparison.

Although there are ethical debates about the use of social robots in dementia (Sharkey, 2014; Sharkey \& Sharkey, 2012), this study highlights that families are open and willing to adopt Paro as a companion animal for their family member. Further, the study also highlights the importance family members hold for psychosocial interventions, including technological innovations such as the robot Paro. Where there is no cure, and where the person with dementia is highly agitated, the promise of an intervention to assist, and possibly show, the positive aspects of a person's behaviour is seen as the provision of hope. Hope, in this sense, is a catalyst that may assist family members to cope with the signs and symptoms of dementia (Cotter, 2009). 
Whilst this study adds important and needed insights into family members' perceptions of Paro, which, to date, has been explored in only one other study (Robinson et al., 2013), there are a number of limitations the reader should be mindful of. First, generalisability is limited, as the study was small in scale $(n=20)$, limited to one Australian state only (Queensland), and involved family members who had either previously owned a pet themselves, or their relative had. Further, the perceptions of family members are limited to the use of Paro or a Plush Toy over a 10-week period, given that this was the time-frame of the larger RCT. A longer duration may have seen perceptions change. Finally, the disappointment expressed by family members about the plush toy may have been exacerbated because of the random allocation of their relatives' facility to the plush toy group rather than the Paro group. Perceptions towards a plush toy, without the potential to receive sessions with Paro, may have seen more positive perceptions.

\section{Conclusion}

Given the limited effectiveness of pharmacological interventions and the growing number of people with dementia, it is important that we consider opportunities, such as the use of robots, to provide companionship for people with dementia. Paro is one type of social robot that is currently available for use with older people with dementia in LTC and, as this study shows, as well as our wider research program, Paro is positively perceived by both family members and care staff (Moyle et al., 2016a), and brings modest but significant improvements in aspects of engagement, mood, and agitation (Moyle et al., accepted for publication). With the opportunities extending and capabilities of robots increasing, there is little doubt that there will be a place for robots, including Paro, in future dementia care. 


\section{References}

Australian Institute of Health and Welfare. (2012). Residential aged care in Australia 201011: A statistical overview. Cat. no. AGE 68. Retrieved from http://www.aihw.gov.au/publication-detail/?id=10737422821

Banerjee, S. (2009). The use of antipsychotic medication for people with dementia: Time for action. Retrieved from http://www.aph.gov.au/DocumentStore.ashx?id=48340346$\underline{1 \mathrm{dbd}-4 \mathrm{e} 37-920 \mathrm{~b}-0 \mathrm{e} 724229047 \mathrm{~b}}$

Bemelmans, R., Gelderblom, G. J., Jonker, P., \& de Witte, L. (2012). Socially assistive robots in elderly care: A systematic review into effects and effectiveness. Journal of the American Medical Directors Assocation, 13, 114-120. doi:10.1016/j.jamda.2010.10.002

Braun, V., \& Clarke, V. (2006). Using thematic analysis in psychology. Qualitative Research in Psychology 3, 77-101. doi:10.1191/1478088706qp063oa

Cotter, V. (2009). Hope in early-stage dementia: A concept analysis. Holistic Nursing Practice, 23, 297-301. doi:10.1097/HNP.0b013e3181b66d4f

Cummings, J., Mintzer, J., Brodaty, H., Sano, M., Banerjee, S., Devanand, D., . . Zhong, K. (2015). Agitation in cognitive disorders: International Psychogeriatric Association provisional consensus clinical and research definition. Intenational Psychogeriatrics, 27, 1-11. doi:10.1017/S1041610214001963

Joranson, N., Pedersen, I., Rokstad, A. M., \& Ihlebaek, C. (2015). Effects on symptoms of agitation and depression in persons with dementia participating in robot-assisted activity: A cluster-randomized controlled trial. Journal of the American Medical Directors Assocation, 16, 867-873. doi:10.1016/j.jamda.2015.05.002

Klapwijk, M. S., Caljouw, M. A., Pieper, M. J., van der Steen, J. T., \& Achterberg, W. P. (2016). Characteristics associated with quality of life in long-term care residents with 
dementia: A cross-sectional study. Dementia and Geriatric Cognitive Disorders, $\mathbf{4 2}$, 186-197. doi:10.1159/000448806

Mordoch, E., Ossterreicher, A., Guse, L., Roger, K., \& Thompson, G. (2013). Use of social commitment robots in the care of elderly people with dementia: A literature review. Maturitas, 74, 14 - 20. doi:10.1016/j.maturitas.2012.10.015

Morley, J. (2011). Dementia-related agitation. Journal of the American Medical Directors Assocation, 12, 611-612.e612. doi:10.1016/j.jamda.2011.08.008

Moyle, W., Beattie, E., Draper, B., Shum, D., Thalib, L., Jones, C., . . Mervin, C. (2015). Effect of an interactive therapeutic robotic animal on engagement, mood states, agitation and psychotrophic drug use in people with dementia: A cluster-randomised controlled trial protocol. BMJ Open, 5. doi:10.1136/bmjopen-2015-009097

Moyle, W., Bramble, M., Jones, C., \& Murfield, J. (2016a). Care staff perceptions of a social robot called Paro and a look-alike Plush Toy: A descriptive qualitative approach. Aging and Mental Health, doi:10.1080/13607863.2016.1262820

Moyle, W., Cooke, M., Beattie, E., Jones, C., Klein, B., Cook, G., \& Gray, C. (2013). Exploring the effect of companion robots on emotional expression in older adults with dementia: A pilot randomized controlled trial. Journal of Gerontological Nursing, 39, 46-53. doi:10.3928/00989134-20130313-03

Moyle, W., ElSaifi N, Draper B, Jones C, Beattie E, Shum D, . . O’Dwyer S. (2017). Pharmacotherapy of persons with dementia in long-term care in Australia: A descriptive audit of central nervous system medications. Current Drug Safety, 12. doi:10.2174/1574886312666170209113203

Moyle, W., Jones C, Sung B, Bramble M, O’Dwyer S, Blumenstein M, \& Estivill-Castro V. (2016b). What effect does an animal robot called CuDDler have on the engagement 
and emotional response of older people with dementia? A pilot feasibility study. International Journal of Social Robotics, 8, 58-65. doi:10.1007/s12369-015-0326-7

Moyle, W., Jones, C., Murfield, J., Thalib, L., Beattie, E., Shum, D., . . Draper, B. (accepted for publication). Use of a robotic seal as a therapeutic tool to improve dementia symptoms: A cluster-randomised controlled trial. Journal of the American Medical Directors Association,

Moyle, W., Venturato L, Griffiths S, Grimbeek P, McAllister M, Oxlade D, \& Murfield J. (2011). Factors influencing quality of life for people with dementia: A qualitative perspective. Aging and Mental Health, 15, 970-977. doi:10.1080/13607863.2011.583620

Petersen, S., Houston, S., Qin, H., Tague, C., \& Studley, J. (2017). The utilization of robotic pets in dementia care. Journal of Alzheimer's Disease, 55, 569-574. doi:10.3233/jad160703

Prince, M., Knapp, M., Guerchet, M., McCrone, P., Prina, M., Comas-Herrera, A., . . . On behalf of Alzheimer's Society. (2014). Dementia UK: Update. Retrieved from https://www.alzheimers.org.uk/download/downloads/id/2323/dementia_uk_update.pd $\underline{f}$

Robinson, H., MacDonald, B. A., Kerse, N., \& Broadbent, E. (2013). Suitability of healthcare robots for a dementia unit and suggested improvements. Journal of the American Medical Directors Assocation, 14, 34-40. doi:10.1016/j.jamda.2012.09.006

Sharkey, A. (2014). Robots and human dignity: A consideration of the effects of robot care on the dignity of older people. Ethics and Information Technology, 16, 63-75. doi:10.1007/s10676-014-9338-5 
Sharkey, A., \& Sharkey, N. (2012). Granny and the robots: Ethical issues in robot care for the elderly. Ethics and Information Technology, 14, 27-40. doi:10.1007/s10676-0109234-6

Takayanagi, K., Kirita, T., \& Shibata, T. (2014). Comparison of verbal and emotional responses of elderly people with mild/moderate dementia and those with severe dementia in responses to seal robot, PARO. Frontiers in Aging Neuroscience, 6, 257. doi:10.3389/fnagi.2014.00257

Thodberg, K., Sørensen, L. U., Videbech, P. B., Poulsen, P. H., Houbak, B., Damgaard, V., . . . Christensen, J. W. (2016). Behavioral responses of nursing home residents to visits from a person with a dog, a robot seal or a toy cat. Anthrozoös, 29, 107-121. doi:10.1080/08927936.2015.1089011

Zimmerman, S., Williams, C. S., Reed, P. S., Boustani, M., Preisser, J. S., Heck, E., \& Sloane, P. D. (2005). Attitudes, stress, and satisfaction of staff who care for residents with dementia. The Gerontologist, 45 Spec No 1, 96-105. 


\section{Table Titles and Figure Captions}

Figure 1. Paro (version 9) Therapeutic Companion Robot (Permission for image given by the National Institute of Advanced Industrial Science and Technology (AIST), Japan)

Table 1. Interview Questions with Family Members $(n=20)$

Table 2. Family Code Book Paro and Plush Toy

Table 3. Family Identification Codes

Table 4. Characteristics of Family Member Participants $(n=20)$ 


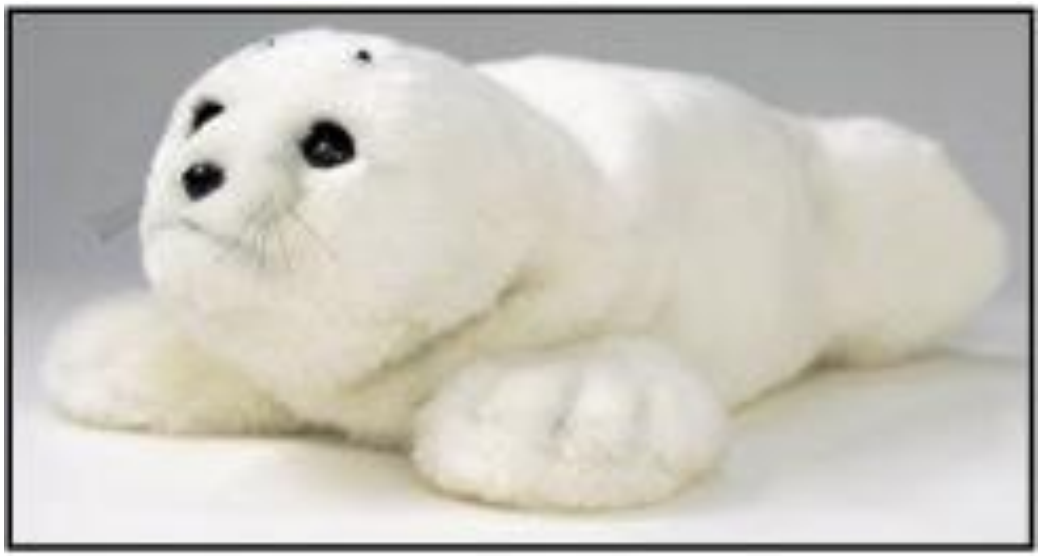

Figure 1. Paro (version 9) Therapeutic Companion Robot (Permission for image given by the National Institute of Advanced Industrial Science and Technology (AIST), Japan) 
Table 1. Interview Questions with Family Members $(n=20)$

1. What were your initial perceptions of the robotic animal/plush toy?

2. Did your initial perception of the robotic animal/plush toy remain or change over time?

3. What, if any, do you see as the benefits of the robotic animal/plush toy in dementia care?

4. What, if any, do you see are the limitations/concerns about the robotic animal/plush toy in dementia care?

5. Tell me how you might use the robotic animal/plush toy in dementia care? (When, where, time of day, individual, group?)

6. Are there any alternatives to the robotic animal/plush toy that could be used in dementia care?

7. Tell me how your perception of the cost of the robotic animal/plush toy, maintenance, and training requirements? 
Table 2. Family Code Book Paro and Plush Toy

\begin{tabular}{|c|c|c|c|}
\hline Content Area & Paro & Plush Toy & Links to Agitation, Mood and Engagement \\
\hline Initial perceptions & $\begin{array}{l}\text { Live Animal } 19 \\
\text { Dog } 17 \\
\text { Animal lover } 11 \\
\text { Great idea } 9 \\
\text { Stimulation } 8 \\
\text { Calming } 5 \\
\text { Cuddly } 3\end{array}$ & $\begin{array}{l}\text { Live animal } 11 \\
\text { Animal lover } 10 \\
\text { Did not see it } 6 \\
\text { Interaction } 5 \\
\text { Comfort } 5 \\
\text { Dog } 5 \\
\text { Sensory stimulation } 4 \\
\text { Improve cognition } 3 \\
\text { Reminiscence } 2\end{array}$ & $\begin{array}{l}\text { Anxiety } \\
\text { Associate with pet dog } \\
\text { Stimulation } \\
\text { Calming } \\
\text { Meaningful activity }\end{array}$ \\
\hline $\begin{array}{l}\text { Changing } \\
\text { perceptions when } \\
\text { seen with relative }\end{array}$ & $\begin{array}{l}\text { Interact } 19 \\
\text { Happy/improve mood } \\
15 \\
\text { Companionship } 14 \\
\text { Stimulation/Breaking } \\
\text { boredom } 9 \\
\text { Contented } 7 \\
\text { Address loneliness } 5 \\
\text { Comfort } 3 \\
\text { Enjoy } 4 \\
\text { Sitting still } 2 \\
\text { Responsibility } 2\end{array}$ & $\begin{array}{l}\text { Disappointment } 6 \\
\text { Did not move } 6 \\
\text { Toy } 6 \\
\text { Did not see it } 5 \\
\text { Did not engage } 5 \\
\text { Big white thing } 4 \\
\text { Knew not real } 4 \\
\text { Did not distract } 3\end{array}$ & $\begin{array}{l}\text { Paro } \\
\text { Emotional needs met } \\
\text { Improve mood } \\
\text { Interaction - help with social isolation } \\
\text { Stimulation } \\
\text { Reduce agitation } \\
\text { Provide comfort } \\
\text { Plush Toy } \\
\text { Disappointment } \\
\text { No therapeutic qualities }\end{array}$ \\
\hline Benefits & $\begin{array}{l}\text { Social interaction } 12 \\
\text { Something to love } 11 \\
\text { Reduce agitation } 8 \\
\text { Stimulation } 8 \\
\text { Focus conversation } 7 \\
\text { Brings back memories } \\
6 \\
\text { Family replacement } 6\end{array}$ & $\begin{array}{l}\text { Needs to move } 10 \\
\text { Discussed benefits of PARO } \\
\text { rather than toy } 10\end{array}$ & $\begin{array}{l}\text { Paro } \\
\text { Reduce psychological triggers } \\
\text { Improvement in interpersonal relationships } \\
\text { Stimulation } \\
\text { Reduce BPSD } \\
\text { Reduce loneliness } \\
\text { Emotional and social engagement with family } \\
\text { Reminiscence }\end{array}$ \\
\hline
\end{tabular}




\begin{tabular}{|c|c|c|c|}
\hline & $\begin{array}{l}\text { Reduce wandering } 1 \\
\text { Distraction } 1 \\
\text { Interactive } 1 \\
\text { Emotional engagement } \\
1\end{array}$ & & \\
\hline \multirow{6}{*}{$\begin{array}{l}\text { Limitations/ } \\
\text { concerns }\end{array}$} & \multirow{6}{*}{$\begin{array}{l}\text { Cost } 10 \\
\text { Heavy } 2 \\
\text { Not familiar pet } 2 \\
\text { Limited movement } 1 \\
\text { Maintaining hygiene } 1\end{array}$} & \multirow{6}{*}{$\begin{array}{l}\text { Not an animal } 10 \\
\text { Cost } 10 \\
\text { Toy } 6 \\
\text { Did not move } 6 \\
\text { Heavy } 5 \\
\text { Could not see seal's eyes } 2\end{array}$} & Paro \\
\hline & & & Too expensive \\
\hline & & & Not familiar \\
\hline & & & Hygiene may be issue \\
\hline & & & Plush Toy \\
\hline & & & Did not move/heavy/could not see seal's eyes \\
\hline \multirow[t]{11}{*}{ Involvement } & \multirow{11}{*}{$\begin{array}{l}\text { Yes } 10 \\
\text { As pet therapy } 10 \\
\text { Group activity } 8 \\
\text { Mornings } 8 \\
\text { Alone in room } 7 \\
\text { Afternoon } 5 \\
\text { Help calm } 5 \\
\text { Focus conversation } 5 \\
\text { Break boredom } 5 \\
\text { Something to love } 4\end{array}$} & \multirow{11}{*}{$\begin{array}{l}\text { Yes } 10 \\
\text { Mutual experience } 1 \\
\text { Afternoon when sad } 1 \\
\text { Communal situations } 1 \\
\text { Socialisation } 1 \\
\text { Weekends } 1 \\
\text { When Mum agitated } 1 \\
\text { Focus conversation } 1 \\
\text { Bring back memories } 1 \\
\text { In room alone } 1\end{array}$} & Paro \\
\hline & & & All family members want to be involved in meaningful \\
\hline & & & activities \\
\hline & & & Aim to meet needs of individual - person centred \\
\hline & & & Something to share and love with person with dementia - \\
\hline & & & perceives PARO to be real (visual agnosia) with \\
\hline & & & encouragement from family - mutual experience. \\
\hline & & & Social experience especially at weekends \\
\hline & & & Happy memories of family and pets \\
\hline & & & Helps with sadness and loneliness \\
\hline & & & Helps with agitation \\
\hline \multirow[t]{3}{*}{ Alternatives } & $\begin{array}{l}\text { Live animal but robotic } \\
\text { animal better } 7\end{array}$ & $\begin{array}{l}\text { Real animal but not practical } \\
6\end{array}$ & Not applicable \\
\hline & Toy but doesn’t interact & Small puppy 1 & \\
\hline & 5 & Ragdoll cat 1 & \\
\hline Further responses & $\begin{array}{l}\text { Enjoyed experience } 3 \\
\text { Interaction when family } \\
\text { not present }\end{array}$ & Helps with cognitive skills 1 & Not applicable \\
\hline
\end{tabular}


Table 3. Family Identification Codes

\begin{tabular}{ll}
\hline Identification Codes & Family Category \\
\hline FD 1 & Daughter 1 \\
FD 2 & Daughter 2 \\
FD 3 & Daughter 3 \\
FD 4 & Daughter 4 \\
FD 5 & Daughter 5 \\
FD 6 & Daughter 6 \\
FD 7 & Daughter 7 \\
FD 8 & Daughter 8 \\
FD 9 & Daughter 9 \\
FD 10 & Daughter 10 \\
FD 11 & Daughter 11 \\
FS 12 & Son 1 \\
FS 13 & Son 2 \\
FS 14 & Son 3 \\
FS 15 & Son 4 \\
FW 16 & Wife 1 \\
FW 17 & Wife 2 \\
FW 18 & Wife 3 \\
FW 19 & Husband 1 \\
FF 20 & Friend 1 \\
\hline
\end{tabular}


Table 4. Characteristics of Family Member Participants $(n=20)$

\begin{tabular}{|c|c|c|}
\hline \multirow[t]{2}{*}{ Family Member Demographics } & $\begin{array}{l}\text { Paro Group } \\
(n=10)\end{array}$ & $\begin{array}{l}\text { Plush Toy Group } \\
\quad(n=10)\end{array}$ \\
\hline & Frequency & Frequency \\
\hline Age (Range; years) & $20-65$ & $20-65$ \\
\hline \multicolumn{3}{|l|}{ Gender } \\
\hline Male & 3 & 2 \\
\hline Female & 7 & 8 \\
\hline \multicolumn{3}{|l|}{ Cultural Background/Nationality } \\
\hline Australian & 3 & 7 \\
\hline Eastern European & 3 & 0 \\
\hline British & 4 & 2 \\
\hline New Zealander & 0 & 1 \\
\hline \multicolumn{3}{|l|}{ Employment/Previous occupation } \\
\hline Management & 7 & 7 \\
\hline Labourer & 1 & - \\
\hline Academic & - & 1 \\
\hline Home Duties & - & 1 \\
\hline Retired & 2 & - \\
\hline Unknown & - & 1 \\
\hline \multicolumn{3}{|l|}{ Relationship to Resident } \\
\hline Daughter & 5 & 6 \\
\hline Son & 2 & 2 \\
\hline Husband & 1 & - \\
\hline Wife & 1 & 2 \\
\hline Friend & 1 & - \\
\hline Power of Attorney for the Resident: Yes & 9 & 10 \\
\hline $\begin{array}{l}\text { Length of Time as Carer for Resident } \\
\text { (Range; years) }\end{array}$ & $2-10$ & $2-14$ \\
\hline $\begin{array}{l}\text { Approximate Number of Visits to Resident } \\
\text { per Month (Range) }\end{array}$ & Daily - once a wk ${ }^{\mathrm{a}}$ & Daily - once a wk \\
\hline $\begin{array}{l}\text { Family Member/Resident previously had a } \\
\text { pet: Yes }\end{array}$ & 10 & 10 \\
\hline
\end{tabular}

